\title{
EQUINE-LIKE G3 ROTAVIRUS IN HUNGARY, 2015 - IS IT A NOVEL INTERGENOGROUP REASSORTANT PANDEMIC STRAIN?
}

\author{
RenÁta Dóró ${ }^{1}$, SzILVIA MARTON ${ }^{1}$, ANETT HORVÁth BARTÓKNÉ ${ }^{1}$, \\ GYÖRGY LENGYEL ${ }^{2}$, ZSÓFIA AGÓCS ${ }^{3}$, FERENC JAKAB ${ }^{4}$ and \\ KRISZTIÁN BÁNYAI ${ }^{1 *}$ \\ ${ }^{1}$ Institute for Veterinary Medical Research, Centre for Agricultural Research, \\ Hungarian Academy of Sciences, Budapest, Hungary \\ ${ }^{2}$ Medical Centre of Hungarian Defense Forces, Force Health Laboratory Institute, \\ Budapest, Hungary \\ ${ }^{3}$ Combined Szent István and Szent László Hospital, Budapest, Hungary \\ ${ }^{4}$ János Szentágothai Research Centre, University of Pécs, Pécs, Hungary
}

(Received: 3 March 2016; accepted: 14 April 2016)

\begin{abstract}
Novel, intergenogroup reassortant G3 rotavirus strains are spreading in at least three continents: Asia, Australia, and Europe. The present study provides evidence that a closely related G3P[8] strain circulated in Hungary during 2015. Whole genome sequencing and phylogenetic analysis showed that the identified strain continues to evolve by reassortment. This observation demonstrates the genomic plasticity of the novel strain, which is thought to be a prerequisite of the success of emerging rotavirus genotypes.
\end{abstract}

Keywords: surveillance, next generation sequencing, phylogenetic analysis

\section{Introduction}

Rotavirus $A$ (RVA) is one of the leading causes of acute dehydrating diarrhoea in infants and young children. Since 2006, the monovalent Rotarix ${ }^{\circledR}$ (GlaxoSmithKline) and the pentavalent RotaTeq ${ }^{\mathbb{B}}$ (Merck) vaccines have been available for routine use in numerous countries worldwide to alleviate the economic and societal burden of RVA infections [1].

*Corresponding author; E-mail: bkrota@hotmail.com

This is an open-access article distributed under the terms of the Creative Commons Attribution License, which permits unrestricted use, distribution, and reproduction in any medium for non-commercial purposes, provided the original author and source are credited. 
With an 11-segmented double-stranded RNA genome and a coding capacity of 11 or 12 proteins (including six structural proteins, VP1 to VP4, VP6, and VP7 and six non-structural proteins, NSP1 to NSP5/6), RVA strains are classified into the genus Rotavirus, family Reoviridae [2]. Classification below the species level includes the assignment of $\mathrm{G}$ and $\mathrm{P}$ type specificities based on the antigenic and genetic differences of the outer capsid proteins, VP7 and VP4, respectively. More recently, the genotyping system has been extended to assign the whole genome based genotype constellation, where Gx-P[x]-Ix-Rx-Cx-Mx-Ax-Nx-Tx-Ex-Hx designates the genotypes of the VP7-VP4-VP6-VP1-VP2-VP3-NSP1-NSP2NSP3-NSP4-NSP5/6 protein-coding genes [3].

Rotavirus strain surveillance is being conducted worldwide to support ongoing vaccination programs by collecting information about changes in strain prevalence and understand whether such changes may be linked to vaccine use. A total of six genotype combinations of the VP7 (G) and VP4 (P) neutralization antigens (i.e., G1P[8], G2P[4], G3P[8], G4P[8], G9P[8], and G12P[8]) are considered medically important worldwide [4]. More recently, whole-genome sequencing studies employing low cost traditional sequencing methods or advanced sequencing technologies have significantly contributed to our understanding of preferred constellations for the backbone genes in various genotypes. The majority of human RVA strains can be readily classified into one of the two homologous whole genome constellations. For example, the genotype 1 constellation is composed of the following genotypes of backbone genes: I1R1-C1-M1-A1-N1-T1-E1-H1 and among the medically important strains mainly express G1P[8], G3P[8], G4P[8], G9P[8], or G12P[8] antigen specificities. On the other hand, the genotype 2 constellation is composed of genotypes I2-R2C2-M2-A2-N2-T2-E2-H2 and is mostly associated with the G2P[4] antigen specificity [5].

To aid vaccine monitoring programs, WHO recommends the use of nested PCR-based genotyping methods of rotavirus strains. In this assay format, a mixture of genotype-specific oligonucleotides is included, which target the G (VP7) types and P (VP4) types of medically important human rotaviruses [6]. No analogous assays have been developed for the backbone genes. In 2012, we initiated a pilot study to implement new, high-throughput sequencing technologies in routine strain surveillance [7]. In the 2015 study, we observed the circulation of novel G3P[8] strains carried on the genotype 2 constellation of backbone genes. Literature review and sequence database search revealed similar strains circulating in other parts of the world. The aim of the present study was to genetically characterize the unusual intergenogroup reassortant strain that carries a $G$ neutralization antigen of putative equine origin. 


\section{Materials and Methods}

RVA positive stool samples were suspended in phosphate-buffered saline, and then the genomic RNA was extracted using the TRIzol method [8]. Complementary DNA was prepared in the presence of $10 \mu \mathrm{M}$ random hexamer tailed by a PCR primer sequence tag [9]. Reverse transcription was performed with the AMV reverse transcriptase (Promega). PCR amplification was carried out using Taq DNA polymerase (Thermo Scientific). About 10-100 ng of random PCR product was subjected to enzymatic fragmentation using the reagents supplied in the NEBNext Fast DNA Fragmentation \& Library Prep Set for Ion Torrent ${ }^{\mathrm{TM}}$ kit (New England Biolabs). The adaptor ligation was performed using reagents from the same kit, whereas barcoded adaptors were retrieved from the Ion Xpress ${ }^{\mathrm{TM}}$ Barcode Adapters (Life Technologies). The library DNA was run on 2\% precast gels, and then products between 300 and 350 bp were used in emulsion PCR. This step was carried out according to the manufacturer's protocol using the Ion PGM Template kit on a OneTouch v2 instrument. Following enrichment of the templated beads, the sequencing protocol recommended for Ion PGM ${ }^{\mathrm{TM}}$ Sequencing 200 Kit v2 on a 316 v2 chip was strictly followed.

Raw sequence data were processed using the CLC Genomics Workbench (http://www.clcbio.com/). Computational work included sequence-read quality trimming and consensus sequence generation by mapping of the obtained sequences to a representative number of reference genotypes. After visual inspection of sequence mappings, a single consensus sequence was created for each gene of all strains. Sequence similarity search was performed through the BLAST server [10]. Multiple alignments were prepared using the Multalin online program [11] and manually adjusted in the GeneDoc software [12], whereas phylogenetic analysis by the maximum-likelihood and the neighbor-joining methods were performed by using the MEGA5 software [13]. For the maximum-likelihood tree, the best fit nucleotide substitution models for each gene were selected based on the Bayesian information criterion as implemented in the MEGA5 software. For the neighbor-joining tree, we used the $p$-distance algorithm. Whole genome similarity comparisons were carried out with the mVISTA platform from the concatenated sequences [14].

\section{Results}

With the whole genome sequencing approach, we determined the genotype constellations of 236 RVA strains collected from the Combined Szent István and Szent László Hospital during the epidemic season of 2015. The hospital provides health services for Budapest and the metropolitan area. In this period, the 
globally most important strains circulating in the study site were as follows: G4P[8] $(n=165,70 \%)$, G9P [8] $(n=36,15.3 \%), \mathrm{G} 1 \mathrm{P}[8](n=4,1.7 \%), \mathrm{G} 3 \mathrm{P}[8](n=3$, $1.3 \%), \mathrm{G} 2 \mathrm{P}[4](n=2,0.8 \%)$, and G12P[8] $(n=1,0.4 \%)$. Mixed antigen types were found in $8.5 \%(n=20)$ of the samples.

Preliminary sequence analysis of the surface antigen encoding genes, VP7 and VP4, revealed that all three G3P[8] strains and two other strains in samples showing mixed genotypes (both G3G9P[8]) had VP7 genes homologous (>99\% nucleotide identity) to novel G3 strains reported from Japan, Thailand, and Australia [15-17]. Also, a sequence homology search through the BLAST engine identified a closely related strain reported from Spain. Based on close phylogenetic relationship between the emerging human G3 strains and an Indian horse rotavirus strain (Figure 1), it was hypothesized in the initial description of the Japanese and the Australian G3 strains that the novel human G3 VP7 lineage may have originated from an equine RVA strain by reassortment event [15, 16]. When analyzing the VP4 gene, we observed that the Hungarian equine-like G3 strains also shared great sequence similarity with cognate genes of the emerging Australian, Thai, and Spanish strains. Of interest, further similarities were identified with Japanese G1P[8] strains, which co-circulated with the Japanese G3P[4] strains carrying the novel G3 VP7 gene. The analysis of other G3P[8] strains detected over the past few years in Hungary revealed no close relatedness with the novel G3P[8] strains (Figure 1).

Analysis of the whole genomic constellation revealed that the novel Hungarian G3P[8] strains detected in 2015 had a genotype 2 constellation of the backbone genes (i.e., I2-R2-C2-M2-A2-N2-T2-E2-H2). Again, in the whole genotype constellation, the Hungarian strains were highly similar to the Australian, Thai, and Japanese strains. One minor difference was a distinct genotype E2 NSP4 variant in the 2013-2014 strains, suggesting that the European equine-like G3 strains could have acquired the NSP4 gene through reassortment from another genotype 2 constellation strain and then the new reassortant strain spread within the continent (Figures 2 and 3). Of note is that the backbone genes showed close relatedness with other intergenogroup reassortant strains, including contemporary Philippine, Thai, and Japanese G1P[8] rotaviruses [17, 18] (Figure 2).

\section{Discussion}

Previous studies indicated that genotype G3, which is the most widespread RVA antigen specificity among mammals and human RVAs may acquire the G3 VP7 gene from various host species. Genotype G3 strains of feline, canine, porcine, and lapin origin have been implicated in the generation of diversity within 


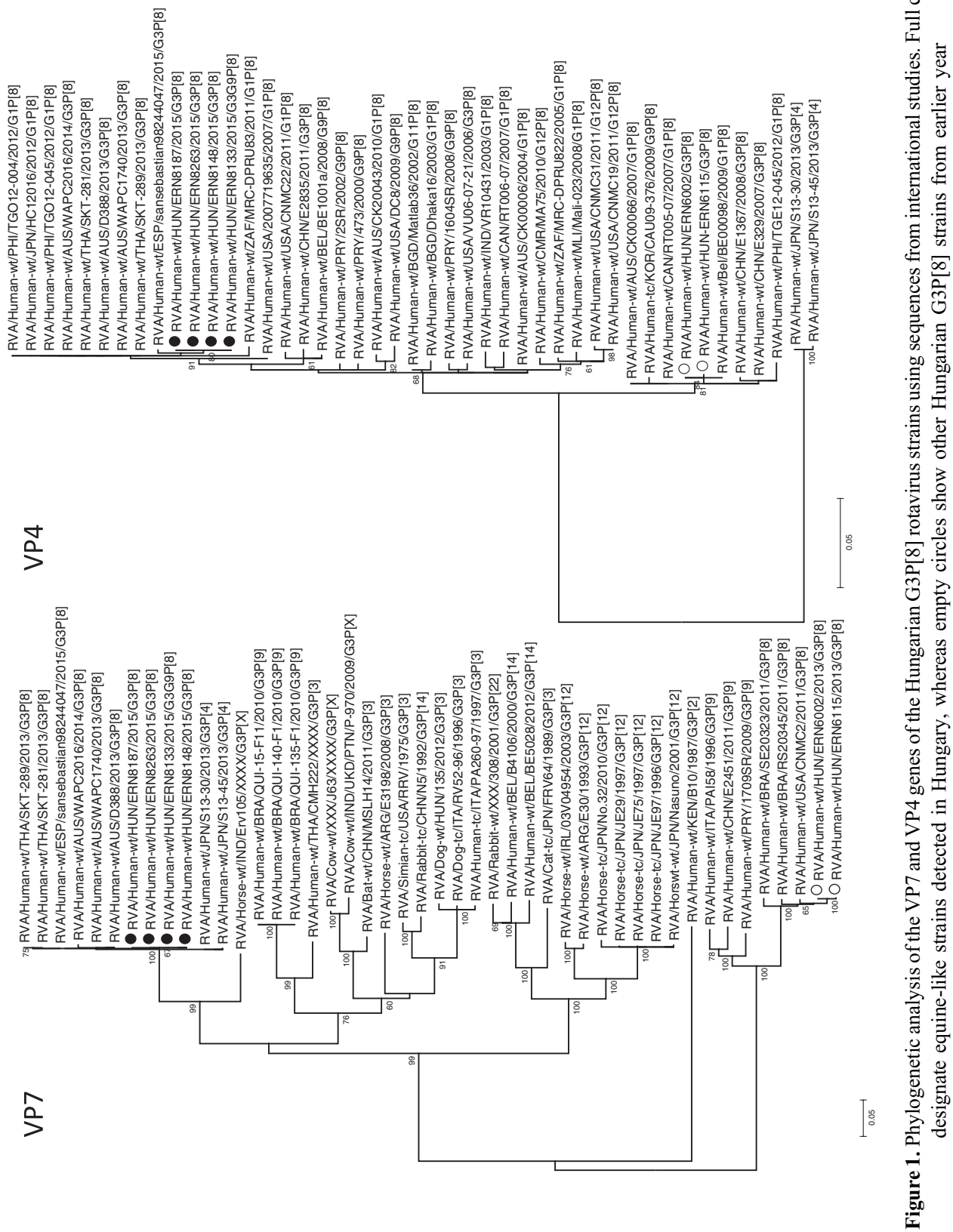




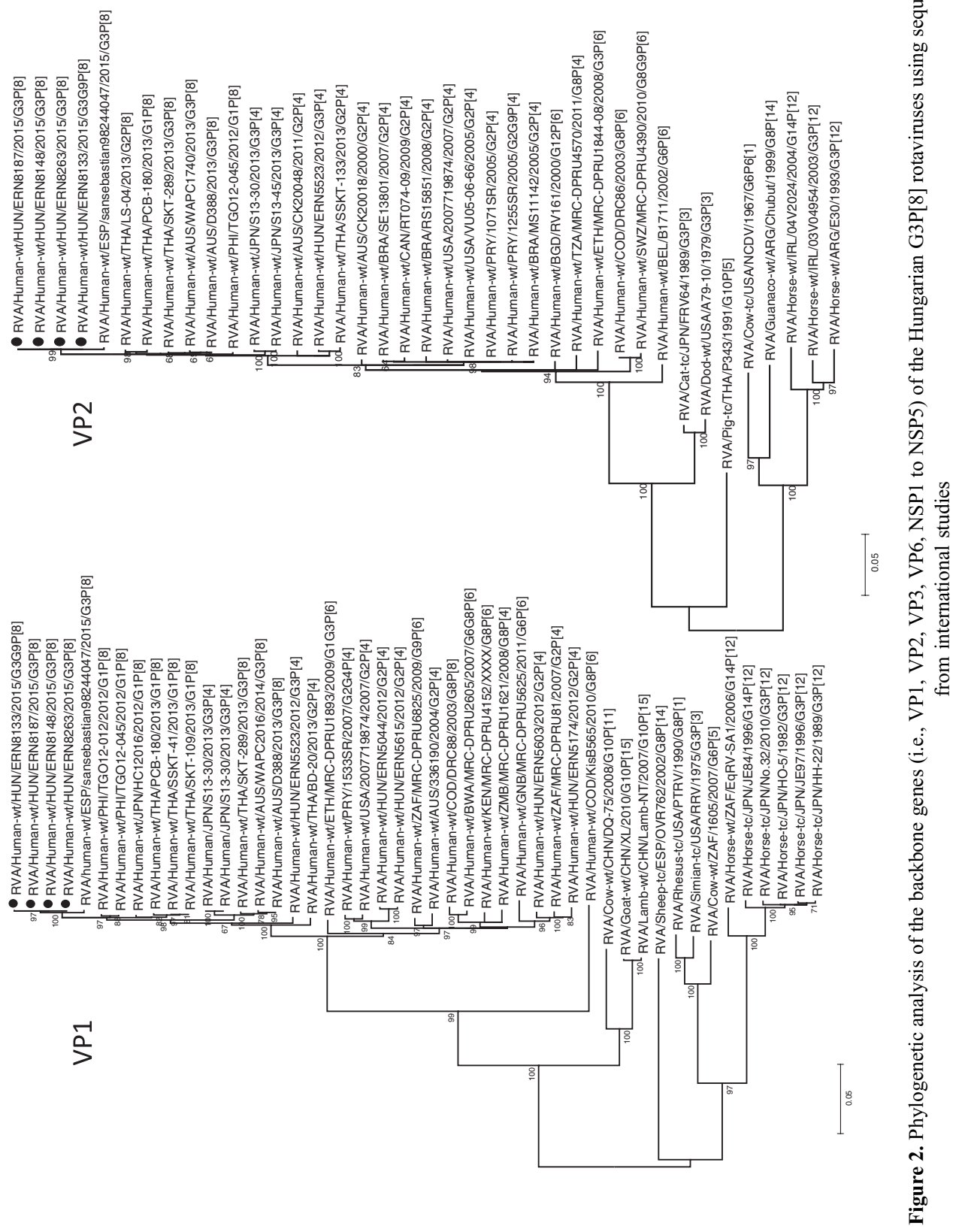



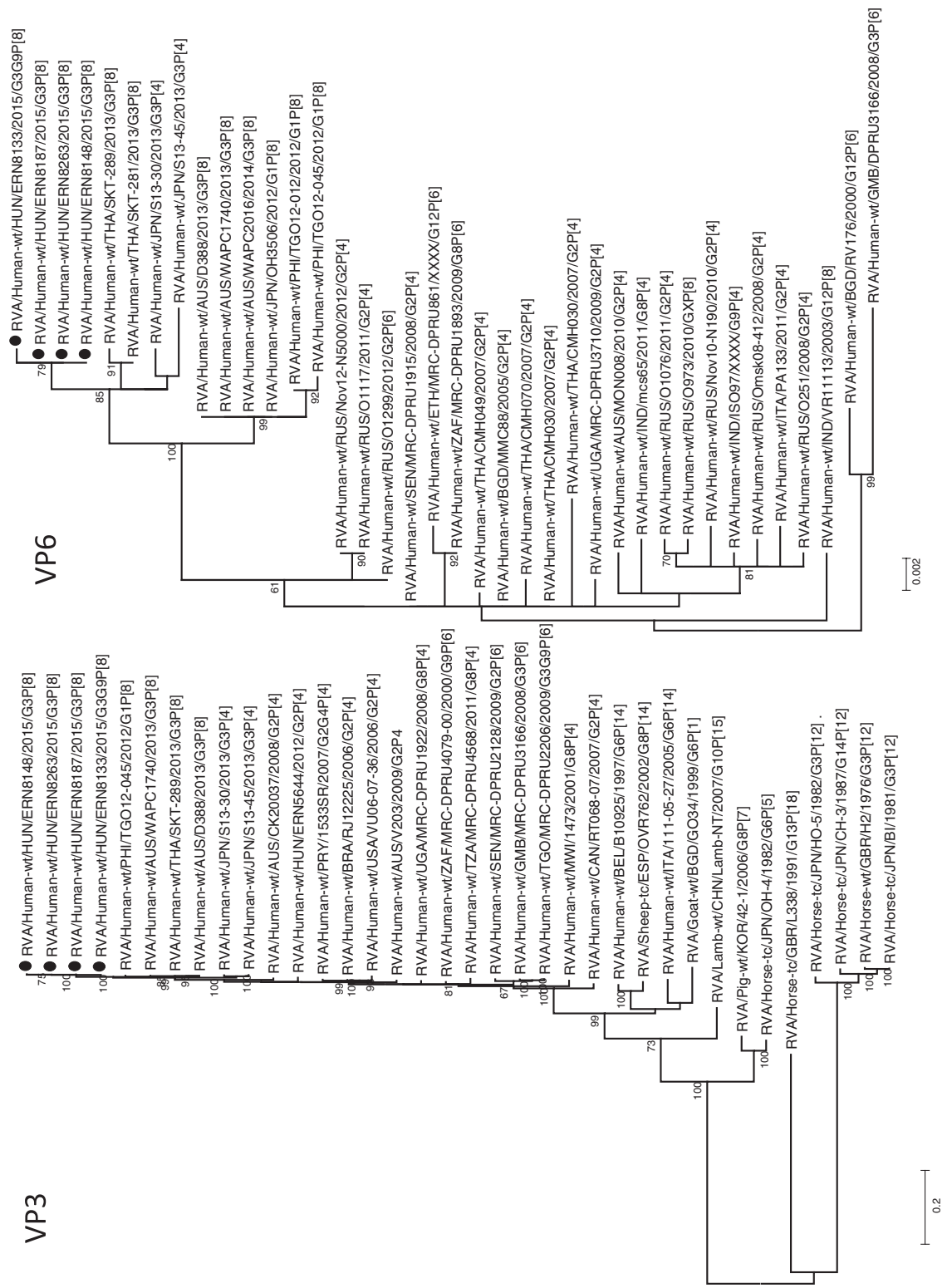


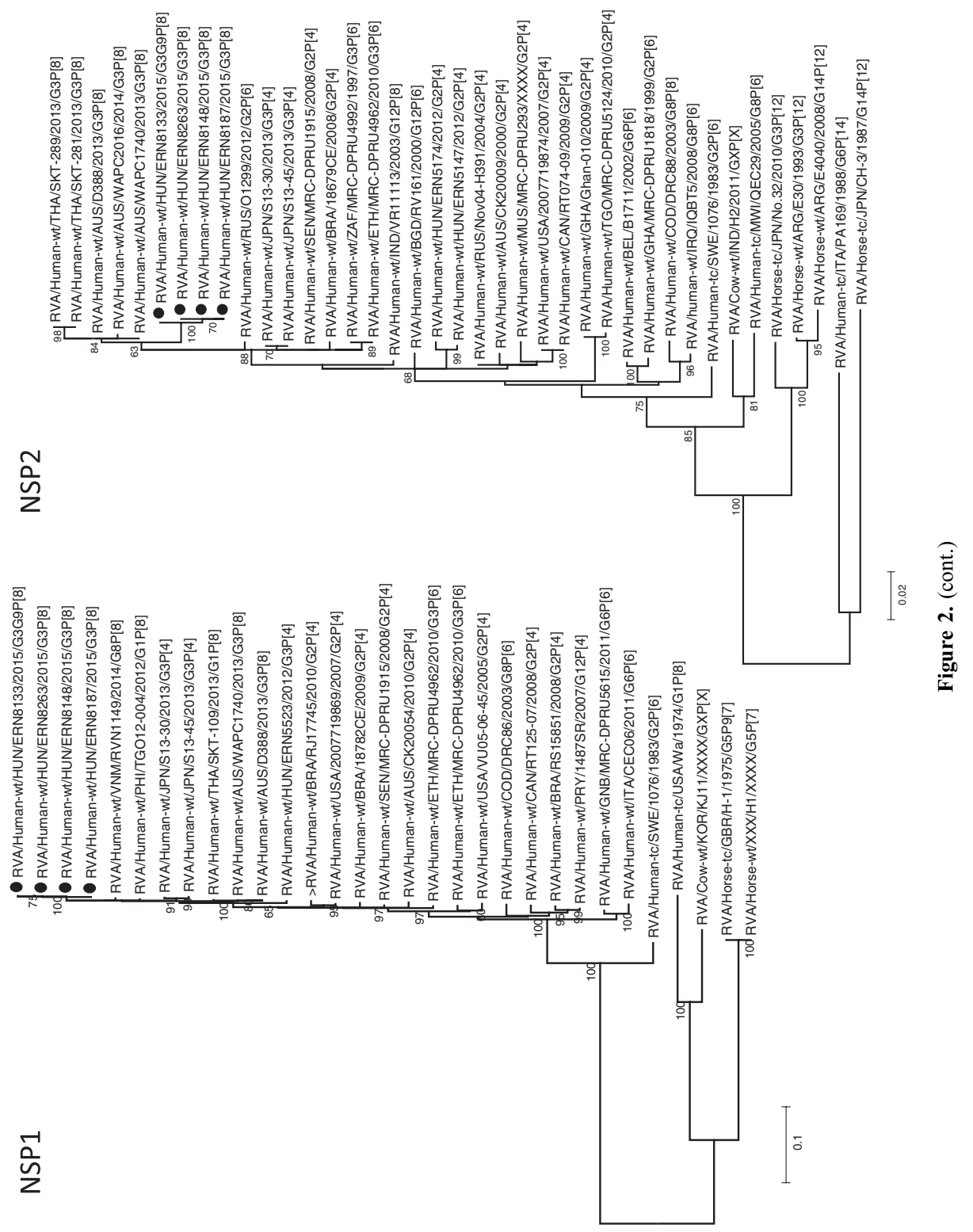




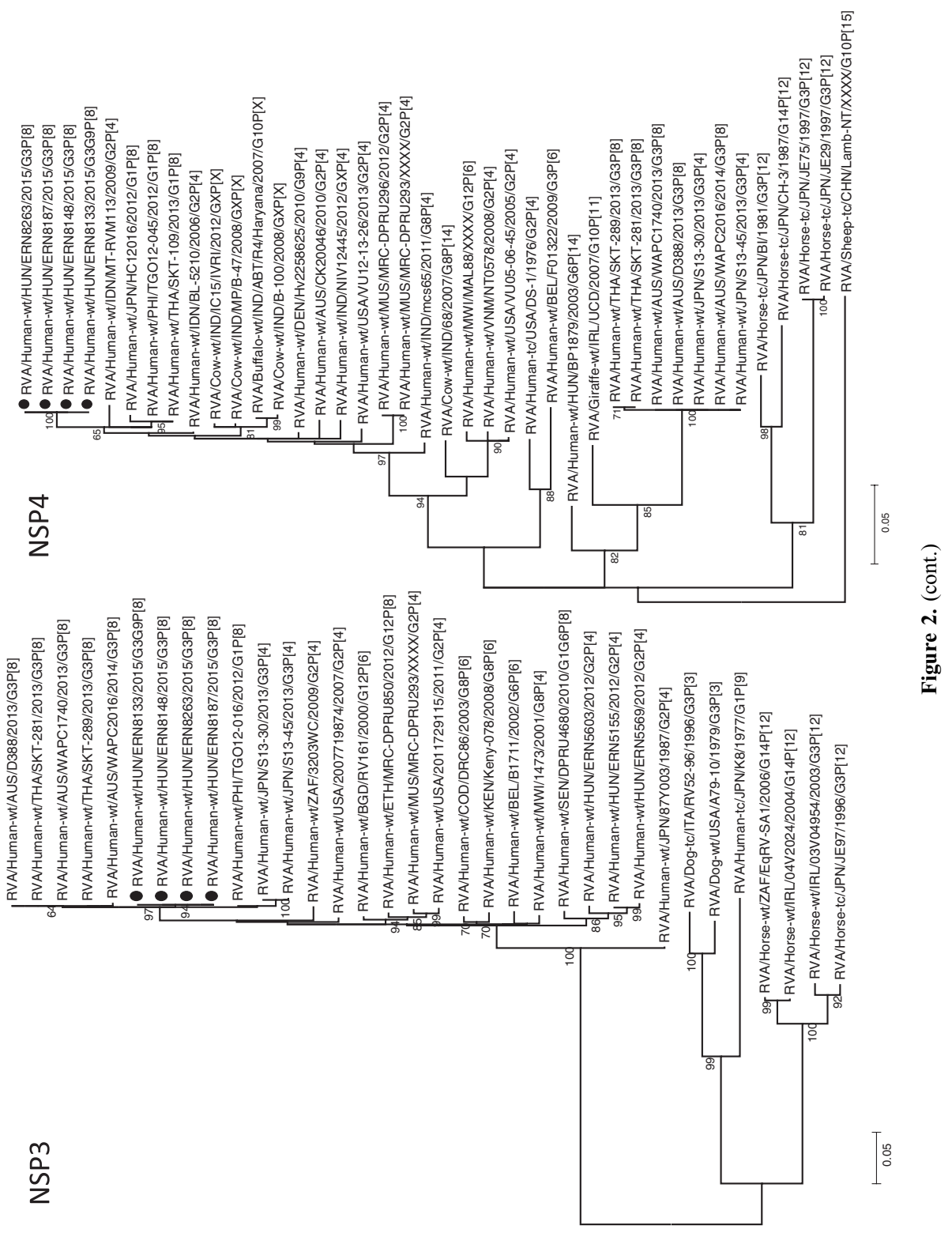




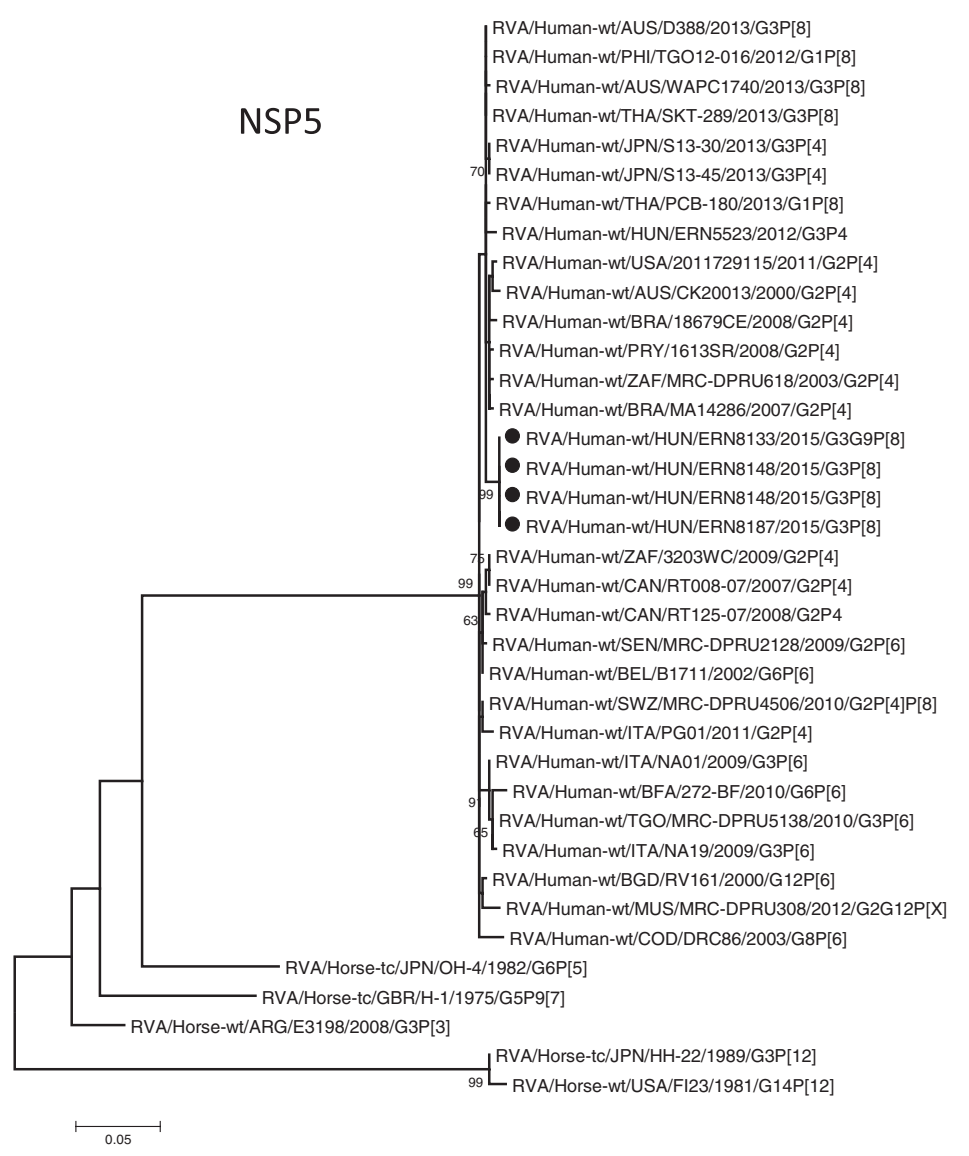

Figure 2. (cont.)

human RVA strains [19]. Published information on the putative equine origin G3 VP7 gene carried on a common human genotype constellation would be the first indication that an equine RVA could serve as a donor of the G3 VP7 gene for a heterologous RVA strain [15-17].

Recent findings including our surveillance data presented here demonstrate that a novel, intergenogroup reassortant G3 strain that carries this putative equine origin VP7 gene emerged in parts of Australia and Asia and also spread in parts of Europe over the past several years [15-17]. Collectively, although data about the new G3 strain is scanty at this moment, lines of evidence suggest that since the first description of the novel human G3 strain in Japan the strain has spread globally and evolved acquiring new VP4 and NSP4 genes through reassortment (Figure 3). Although, at present, it is not possible to delineate the accurate temporal order of 


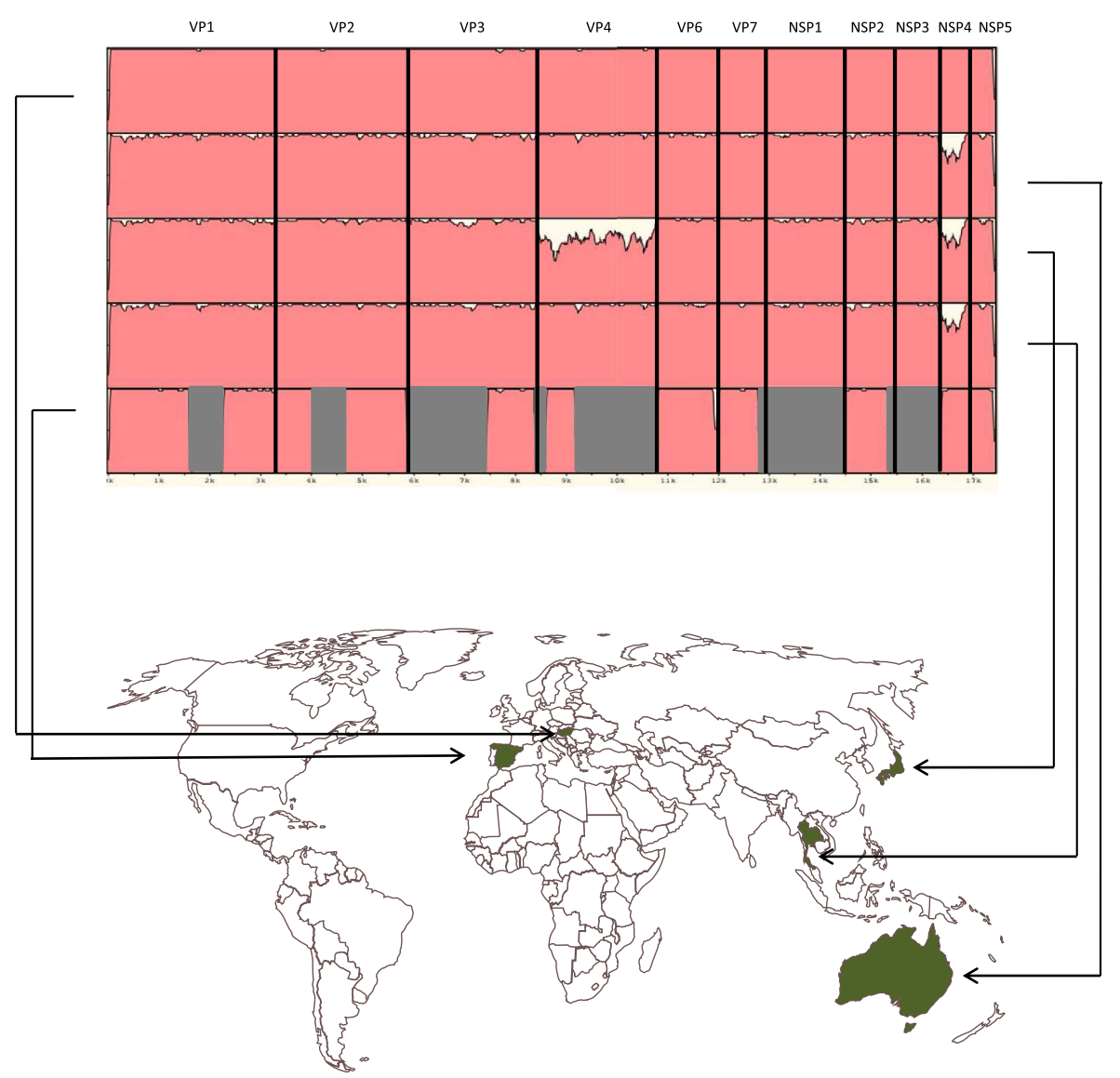

Figure 3. World map showing the countries where the novel equine-like G3 strains were detected. Whole-genome comparison of a Hungarian strain in the mVISTA module [11] with representative equine-like G3 strains from Japan, Australia, Thailand, and Spain shows the greatest genomic conservation with the Spanish strain (gray color shows missing sequence information). The Japanese strains had a different VP4 and NSP4 variant, whereas the Australian and Thai strains differed only in the NSP4 gene from the Hungarian intergenogroup G3P[8] strain. Representative strains were as follows: Hungary, RVA/Human-wt/HUN/ERN8263/2015/G3P[8]; Australia, RVA/Human-wt/ AUS/WAPC2016/2014/G3P[8]; Japan, RVA/Human-wt/JPN/S13-30/2013/G3P[4]; Thailand, RVA/Human-wt/THA/SKT-289/2013/G3P[8]; Spain, RVA/Human-wt/ESP/ sansebastian98244047/2015/G3P[8]

such reassortment events, this pattern of geographic spread of a novel G3 RVA antigen specificity resembles the global emergence of strains carrying particular genetic lineages of the G9 and G12 VP7 genes on heterogeneous backbone gene constellations $[20,21]$. 
Thus far, post licensure strain surveillance has not revealed any consistent trends in strain selection due to vaccine use; however, it appears an interesting finding that the greatest prevalence of these novel G3 strains was detected in high vaccine coverage populations [16]. Thus, more information will be needed to appropriately evaluate the impact of emergence of the novel reassortant G3 strain on regional and global strain prevalence over time. Introduction of whole genome sequencing in routine strain typing will play a key role in the recognition of unusual genotype constellations and the assessment of their importance in the post rotavirus vaccine licensure era.

\section{Acknowledgements}

The study was supported by the Hungarian Scientific Research Fund (OTKA, T100727). Additional support was obtained from GlaxoSmithKline (GSK) Biologicals and Sanofi-Pasteur-MSD (SPMSD) in the form of unrestricted collaborative grants administered through the Health Protection Agency (London, UK). The "Lendület" Pathogen Discovery Research Group was supported by the Lendület program (awarded by the Hungarian Academy of Sciences). SM was supported by the Bolyai Scholarship Program.

\section{Conflict of Interest}

None declared.

\section{References}

1. Dennehy, P. H.: Rotavirus vaccines: An overview. Clin Microbiol Rev 21, 198-208 (2008).

2. Desselberger, U.: Rotaviruses. Virus Res 190, 75-96 (2014).

3. Matthijnssens, J., Ciarlet, M., Heiman, E., Arijs, I., Delbeke, T., McDonald, S. M., Palombo, E. A., Iturriza-Gómara, M., Maes, P., Patton, J. T., Rahman, M., Van Ranst, M.: Full genome-based classification of rotaviruses reveals a common origin between human Wa-Like and porcine rotavirus strains and human DS-1-like and bovine rotavirus strains. J Virol 82, 3204-3219 (2008).

4. Dóró, R., László, B., Martella, V., Leshem, E., Gentsch, J., Parashar, U., Bányai, K.: Review of global rotavirus strain prevalence data from six years post vaccine licensure surveillance: Is there evidence of strain selection from vaccine pressure? Infect Genet Evol 28, 446-461 (2014).

5. Matthijnssens, J., Van Ranst, M.: Genotype constellation and evolution of group A rotaviruses infecting humans. Curr Opin Virol 2, 426-433 (2012).

6. WHO: Manual of rotavirus detection and characterization methods. 2009, pp. 1-146. Available from: http://whqlibdoc.who.int/hq/2008/who_ivb_08.17_eng.pdf 
7. Dóró, R., Mihalov-Kovács, E., Marton, S., László, B., Deák, J., Jakab, F., Juhász, Á., Kisfali, P., Martella, V., Melegh, B., Molnár, P., Sántha, I., Schneider, F., Bányai, K.: Large-scale whole genome sequencing identifies country-wide spread of an emerging G9P[8] rotavirus strain in Hungary, 2012. Infect Genet Evol 28, 495-512 (2014).

8. Jakab, F., Meleg, E., Bányai, K., Melegh, B., Tímár, L., Péterfai, J., Szúcs, G.: One-year survey of astrovirus infection in children with gastroenteritis in a large hospital in Hungary: Occurrence and genetic analysis of astroviruses. J Med Virol 74, 71-77 (2004).

9. Djikeng, A., Halpin, R., Kuzmickas, R., Depasse, J., Feldblyum, J., Sengamalay, N., Afonso, C., Zhang, X., Anderson, N. G., Ghedin, E., Spiro, D. J.: Viral genome sequencing by random priming methods. BMC Genomics 9,5 (2008).

10. Altschul, S. F., Gish, W., Miller, W., Myers, E. W., Lipman, D. J.: Basic local alignment search tool. J Mol Biol 215, 403-410 (1990).

11. Corpet, F.: Multiple sequence alignment with hierarchical clustering. Nucl Acids Res 16, 10881-10890 (1988).

12. Nicholas, K. B., Nicholas, H. B., Deerfield, D. W.: GeneDoc: Analysis and visualization of genetic variation. EMBNET News 4, 1-4 (1997).

13. Tamura, K., Peterson, D., Peterson, N., Stecher, G., Nei, M., Kumar, S.: MEGA5: Molecular evolutionary genetics analysis using maximum likelihood, evolutionary distance, and maximum parsimony methods. Mol Biol Evol 28, 2731-2739 (2011).

14. Frazer, K. A., Pachter, L., Poliakov, A., Rubin, E. M., Dubchak, I.: VISTA: Computational tools for comparative genomics. Nucleic Acids Res 32, W273-W279 (2004).

15. Malasao, R., Saito, M., Suzuki, A., Imagawa, T., Nukiwa-Soma, N., Tohma, K., Liu, X., Okamoto, M., Chaimongkol, N., Dapat, C., Kawamura, K., Kayama, Y., Masago, Y., Omura, T., Oshitani, H.: Human G3P[4] rotavirus obtained in Japan, 2013, possibly emerged through a human-equine rotavirus reassortment event. Virus Genes 50, 129-133 (2015).

16. Cowley, D., Donato, C. M., Roczo-Farkas, S., Kirkwood, C. D.: Emergence of a novel equine-like G3P[8] inter-genogroup reassortant rotavirus strain associated with gastroenteritis in Australian children. J Gen Virol 97, 403-410 (2016).

17. Komoto, S., Tacharoenmuang, R., Guntapong, R., Ide, T., Haga, K., Katayama, K., Kato, T., Ouchi, Y., Kurahashi, H., Tsuji, T., Sangkitporn, S., Taniguchi, K.: Emergence and characterization of unusual DS-1-Like G1P[8] rotavirus strains in children with diarrhea in Thailand. PLoS One 10, e0141739 (2015).

18. Komoto, S., Tacharoenmuang, R., Guntapong, R., Ide, T., Tsuji, T., Yoshikawa, T., Tharmaphornpilas, P., Sangkitporn, S., Taniguchi, K.: Reassortment of human and animal rotavirus gene segments in emerging DS-1-Like G1P[8] rotavirus strains. PLoS One 11, e0148416 (2016).

19. Dóró, R., Farkas, S. L., Martella, V., Bányai, K.: Zoonotic transmission of rotavirus: Surveillance and control. Expert Rev Anti Infect Ther 13, 1337-1350 (2015).

20. Ramachandran, M., Kirkwood, C. D., Unicomb, L., Cunliffe, N. A., Ward, R. L., Bhan, M. K., Clark, H. F., Glass, R. I., Gentsch, J. R.: Molecular characterization of serotype G9 rotavirus strains from a global collection. Virology 278, 436-444 (2000).

21. Rahman, M., Matthijnssens, J., Yang, X., Delbeke, T., Arijs, I., Taniguchi, K., IturrizaGómara, M., Iftekharuddin, N., Azim, T., Van Ranst, M.: Evolutionary history and global spread of the emerging G12 human rotaviruses. J Virol 81, 2382-2390 (2007). 